\title{
Hydrogen Measurement
}

National Cancer Institute

\section{Source}

National Cancer Institute. Hydrogen Measurement. NCI Thesaurus. Code C102275.

The determination of the amount of hydrogen present in a sample. 